\title{
Electrodeposition of Polypyrrole/Reduced Graphene Oxide/Iron Oxide Nanocomposite as Supercapacitor Electrode Material
}

\author{
Y. C. Eeu, ${ }^{1}$ H. N. Lim, ${ }^{1,2}$ Y. S. Lim, ${ }^{1}$ S. A. Zakarya, ${ }^{1}$ and N. M. Huang ${ }^{3}$ \\ ${ }^{1}$ Department of Chemistry, Faculty of Science, Universiti Putra Malaysia, 43400 Serdang, Selangor, Malaysia \\ ${ }^{2}$ Functional Device Laboratory, Institute of Advanced Technology, Universiti Putra Malaysia, 43400 Serdang, Selangor, Malaysia \\ ${ }^{3}$ Low Dimensional Materials Research Centre, Department of Physics, Faculty of Science, University of Malaya, \\ 50603 Kuala Lumpur, Malaysia
}

Correspondence should be addressed to H. N. Lim; hongngee@upm.edu.my

Received 12 September 2013; Revised 4 November 2013; Accepted 4 November 2013

Academic Editor: Zhenhui Kang

Copyright (C) 2013 Y. C. Eeu et al. This is an open access article distributed under the Creative Commons Attribution License, which permits unrestricted use, distribution, and reproduction in any medium, provided the original work is properly cited.

Polypyrrole (PPy) was reinforced with reduced graphene oxide (RGO) and iron oxide to achieve electrochemical stability and enhancement. The ternary nanocomposite film was prepared using a facile one-pot chronoamperometry approach, which is inexpensive and experimentally friendly. The field emission scanning electron microscopy (FESEM) image shows a layered morphology of the ternary nanocomposite film as opposed to the dendritic structure of PPy, suggesting hybridization of the three materials during electrodeposition. X-ray diffraction (XRD) profile shows the presence of $\mathrm{Fe}_{2} \mathrm{O}_{3}$ in the ternary nanocomposite. Cyclic voltammetry (CV) analysis illustrates enhanced current for the nanocomposite by twofold and fourfold compared to its binary (PPy/RGO) and individual (PPy) counterparts, respectively. The ternary nanocomposite film exhibited excellent specific capacitance retention even after 200 cycles of charge/discharge.

\section{Introduction}

The increase in affluence in developing countries results in the need of high energy consumption. Therefore, energy sustainability is of significant concern, especially when the depletion of fossil fuels is also factored in. Supercapacitors, also known as ultracapacitors or electrochemical supercapacitors, have several important characteristics, including prolonged life cycle, higher power density than batteries, and higher energy density than conventional capacitors which have driven their use in pulse power and power backup applications. According to the mechanism of charge storage, supercapacitors can be classified as electric double layer capacitors (EDLCs), where charge is stored at the electrode/electrolyte interface, and pseudocapacitors where the charge is stored mainly by Faradaic reactions on the surface of the electrode materials [1].

PPy is an inexpensive and environmentally friendly pseudocapacitor, which has been used due to its excellent properties such as low density, high conductivity, high capacitance value (about $200 \mathrm{Fg}^{-1}$ ), and ease in preparation $[2,3]$. However, their poor cycling stability, brittleness, and weak tensile strength impede their real applications [4]. Therefore, PPy has been hybridized with EDLC-based carbon materials to overcome the shortcomings [5].

Graphene is an atomically thick, two-dimensional sheet composed of $\mathrm{sp}^{2}$ carbon atoms arranged in a honeycomb structure. It emerges as an intriguing carbon material with potential for electrochemical energy storage device applications due to its superb characteristics of chemical stability, high electrical conductivity, and large surface area $[6,7]$. Graphene is used in combination with other nanomaterials to produce a new nanostructured compound which will maximize the supercapacitance properties [8]. Graphene is popularly produced from the chemical oxidation approach followed by reduction, owing to its ease of synthesis in scalable quantity [9]. The complementary electrochemical and mechanical properties of PPy and graphene result in the 
composite of the two materials achieving high capacitance values, up to $500 \mathrm{Fg}^{-1}$, and improved cycling stability [10-14].

The presence of pseudocapacitor metal oxide has been reported to increase capacitance properties of a nanocomposite [15]. Iron oxide is an environmentaly friendly transition metal oxide as well as being one of the most abundant and low-cost options. It is utilized as a pseudocapacitive material as it has specific capacitances of up to $165 \mathrm{Fg}^{-1}[16]$.

A ternary electrode material consisting of graphene, PPy, and metal oxide exhibits excellent electrochemical performance which arises from the synergistic effect between these three components. The well-dispersed graphene worked as a framework to sustain the pseudocapacitive materials of metal oxide and PPy. Moreover, the aggregation of metal oxide during charge/discharge cycling is restricted by the PPy film [17].

In this work, PPy/RGO/iron oxide nanocomposite was synthesized via electrodeposition strategy. Electrosynthesis is an oxidant-free process in which the conducting polymer naturally formed a continuous thin film on the electrode [18]. The capacitance properties of the nanocomposite were investigated for its potential in real application as a supercapacitor.

\section{Materials and Methods}

Graphite powder was obtained from Ashbury Graphite Mills Inc., code number 3061. Sulphuric acid $\left(\mathrm{H}_{2} \mathrm{SO}_{4}, 95-98 \%\right)$, phosphoric acid $\left(\mathrm{H}_{3} \mathrm{PO}_{4}, 85 \%\right)$, potassium permanganate $\left(\mathrm{KMnO}_{4}, 99.9 \%\right)$, and hydrogen peroxide $\left(\mathrm{H}_{2} \mathrm{O}_{2}, 30 \%\right)$ were purchased from Systerm, Malaysia. Hydrogen chloride $(\mathrm{HCl}$, $37 \%)$ and iron (II) sulfate $\left(\mathrm{FeSO}_{4}, 99 \%\right)$ were purchased from Sigma-Aldrich. Sodium p-toluenesulfonate (NapTS, 98\%) and potassium chloride $(\mathrm{KCl}, 99.5 \%)$ were purchased from Merck and BDH Chemicals, respectively. Pyrrole (99\%, Acros organic) was stored in $0^{\circ} \mathrm{C}$ and distilled prior to use.

GO was synthesized using a simplified Hummer's method [9]. GO was prepared by adding $3 \mathrm{~g}$ of graphite flakes to a mixture of $\mathrm{H}_{2} \mathrm{SO}_{4}: \mathrm{H}_{3} \mathrm{PO}_{4}(360 \mathrm{~mL}: 40 \mathrm{~mL})$ and $18 \mathrm{~g}$ of $\mathrm{KMnO}_{4}$ and was stirred during mixing. The mixture was stirred for three days to ensure a complete oxidation of graphite. During the oxidation, the color of the mixture changed from dark purplish green to dark brown. The oxidation process was stopped by slowly adding $28 \mathrm{~mL}$ of $\mathrm{H}_{2} \mathrm{O}_{2}$ solution. Meanwhile, the color changed to light brown, indicating the high oxidation of graphite. The GO formed was washed with $1.0 \mathrm{M}$ of $\mathrm{HCl}$ and deionized water three times via centrifugation. During washing, the GO underwent exfoliation and resulted in the thickening of GO into GO gel. The concentration of GO prepared was $15.5 \mathrm{mg} / \mathrm{mL}$.

$\mathrm{PPy} / \mathrm{RGO} / \mathrm{Fe}_{2} \mathrm{O}_{3}$ nanocomposite film was synthesized by using chronoamperometry from an aqueous solution in a pot. The electrodeposition of the nanocomposite was synthesized using a potentiostat model Reference 600 at room temperature. The circuit in the compartment was set up using a three-electrode system where a graphite rod worked as a counter electrode, a nindium tin oxide glass slide (ITO) as a working electrode, and a saturated calomel electrode (SCE) as a reference electrode. The electrolyte consisted of $0.1 \mathrm{M}$ of pyrrole, $1.0 \mathrm{mg} / \mathrm{mL}$ of GO, $0.1 \mathrm{M}$ of NapTS, and $7 \mathrm{mM}$ of $\mathrm{FeSO}_{4}$ in $50 \mathrm{~mL}$ of aqueous solution. Electrodeposition was performed at a constant potential of $+0.8 \mathrm{~V}$ (vs. SCE).

XRD was obtained using Siemens D5000. FESEM was performed using FEI NOVA SEM 400. HRTEM was observed using JEOL JEM-2100 F. The electrochemical properties of the nanocomposites were measured by cyclic voltammetry (CV), galvanostatic charge/discharge, and electrochemical impedance spectroscopy (EIS) using Gamry Reference 600. All the electrochemical measurements were carried out in an electrochemistry cell with a three-electrode cell system. A platinum wire and an $\mathrm{Ag} / \mathrm{AgCl}$ electrode were used as a counter electrode and a reference electrode, respectively, and the nanocomposite film was used directly as a working electrode. The specific capacitance is calculated from galvanostatic charge/discharge using

$$
\text { Specific Capacitance }=\frac{I \times \Delta t}{m \times \Delta V},
$$

where $I$ is current applied, $\mathrm{A} / \mathrm{g} ; \Delta t$ is time taken for discharge phase, $s ; m$ is mass of sample; $g$ and $\Delta V$ are the potential change during discharge phase, $\mathrm{V}$.

\section{Results and Discussion}

3.1. FESEM and XRD. All the XRD patterns show the peaks of ITO at $30.34^{\circ}, 35.22^{\circ}, 50.69^{\circ}$, and $60.36^{\circ}$ (Figure $1(\mathrm{a})$ ). Nevertheless, the peak intensities of ITO diminished distinctly after the films were electrodeposited onto the surface of ITO, suggesting a thin layer of the samples adhering onto the surface of ITO after electrodeposition. The XRD pattern of pure PPy consists of a broad peak at $2 \theta=$ $26^{\circ}$, indicating its amorphous nature [17]. The PPy/RGO nanocomposite film presents crystalline peaks similar to that of PPy film, indicating that no additional crystalline phase has been introduced into the nanocomposite [10]. The typical peak of GO at approximately $9^{\circ}$ disappears for both the binary and ternary nanocomposites, which is evidence of the reduction of GO. In Figure 1(b), the series of diffraction peaks for the ternary nanocomposite film at $26.30^{\circ}, 37.51^{\circ}, 40.38^{\circ}$, and $55.74^{\circ}$ are assigned to reflections from the (211), (222), (321), and (510) crystal planes of $\mathrm{Fe}_{2} \mathrm{O}_{3}$ (JCPDS 39-1346), respectively $[19,20]$.

PPy exhibits sea anemone-like morphology (Figure 2(a)), as opposed to the layered sandwich structure of PPy/RGO/ $\mathrm{Fe}_{2} \mathrm{O}_{3}$ (Figure 2(b)). The stark contrast between the two samples clearly shows that a new hybrid has been materialized from electrodeposition. The PPy and $\mathrm{Fe}_{2} \mathrm{O}_{3}$ components are successfully integrated uniformly within the RGO matrix. This implies that the RGO, acts not only as an EDLC material to enhance the supercapacitance of the nanocomposite, but also as a good support for the embedment of organic and inorganic substances.

3.2. $\mathrm{CV}$ and Charge/Discharge Analysis. The $\mathrm{CV}$ analysis was performed to investigate the changes in the electrochemical performance of PPy and the nanocomposite films. Figure 3(a) compares the $\mathrm{CV}$ curves of the samples at a scan rate of 


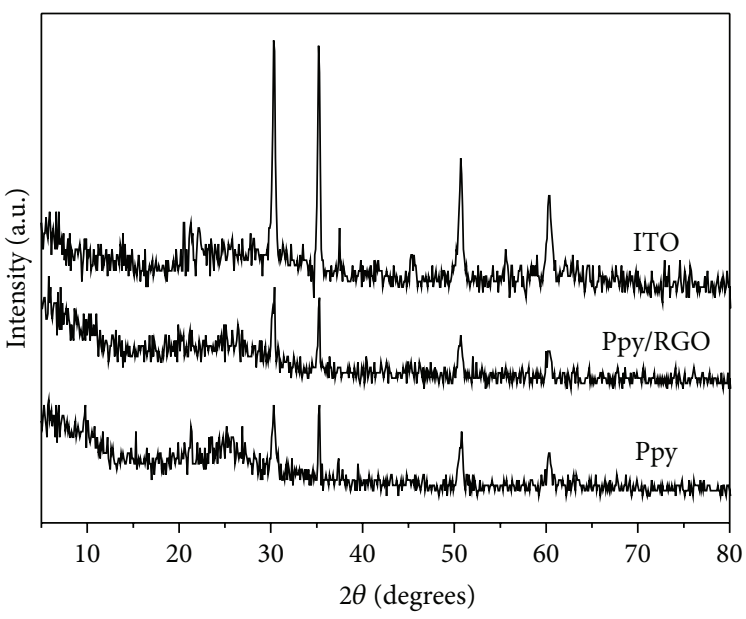

(a)

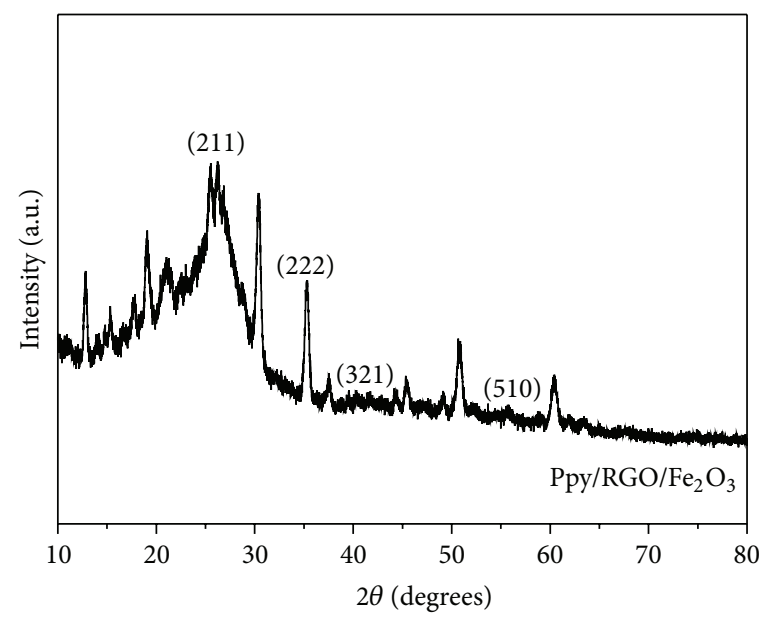

(b)

Figure 1: XRD pattern of (a) ITO, PPy/RGO, PPy and (b) PPy/RGO/Fe $\mathrm{O}_{3}$.

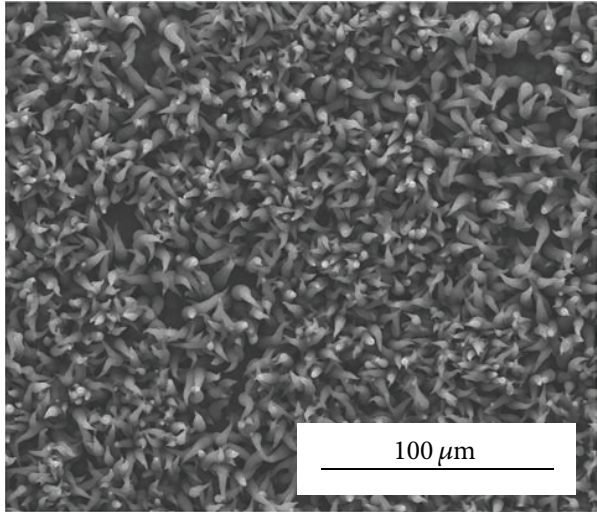

(a)

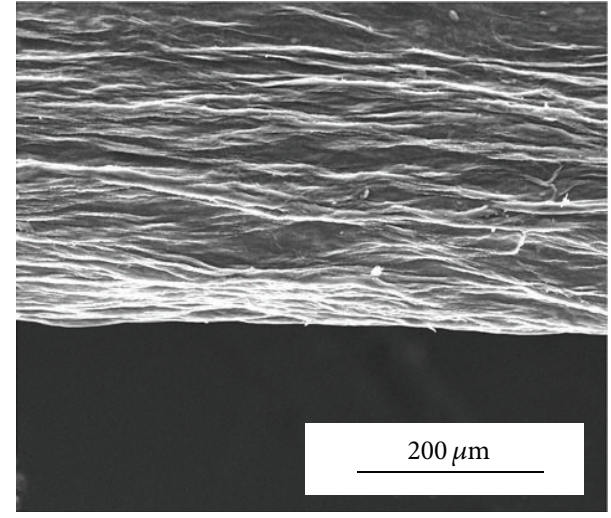

(b)

Figure 2: FESEM image of (a) PPy and (b) $\mathrm{PPy} / \mathrm{RGO} / \mathrm{Fe}_{2} \mathrm{O}_{3}$.

$50 \mathrm{mV} / \mathrm{s}$ in $1.0 \mathrm{M}$ of $\mathrm{KCl}$. The current of the ternary nanocomposite is enhanced by twofold and fourfold compared to its binary and individual counterparts, respectively. The $\mathrm{CV}$ curve of PPy shows deviation from the rectangular form, indicating pseudocapacitive contribution from PPy. With the inclusion of RGO, the nanocomposite films exhibit a quasirectangular curve, evident of EDLC contribution from RGO. From the CV curves, the larger current response of the sample corresponds to a higher capacitive performance. The enhanced current in the PPy/RGO compared to that of PPy can be attributed to the formation of conductive graphene network in PPy matrix. Upon inclusion of $\mathrm{Fe}_{2} \mathrm{O}_{3}$, a further increase of the quasi-rectangular loop is observed, which is evidence of enhanced capacitive performance of the ternary nanocomposite film. The improved capacitive performance could be attributed to the $\mathrm{Fe}_{2} \mathrm{O}_{3}$, which increases the redox activity of nanocomposite.

Figure 3(b) demonstrates the galvanostatic charge/discharge curves at a current density of $0.5 \mathrm{~A} / \mathrm{g}$. All the curves show slight deviation from the triangular shape, indicating the involvement of the Faradaic reaction process of $\mathrm{PPy}$ and $\mathrm{Fe}_{2} \mathrm{O}_{3}$. The specific capacitance of the PPy/RGO/Fe $\mathrm{O}_{3}$ is $125.7 \mathrm{~F} / \mathrm{g}$, whereas the $\mathrm{PPy} / \mathrm{RGO}$ and $\mathrm{PPy}$ electrodes only display 93.3 and $76.6 \mathrm{~F} / \mathrm{g}$, as calculated from the charge/discharge curves using (1). During the growth of the $\mathrm{PPy} / \mathrm{RGO} / \mathrm{Fe}_{2} \mathrm{O}_{3}$ nanocomposite, the PPy and $\mathrm{Fe}_{2} \mathrm{O}_{3}$ components coated the surfaces of individual RGO sheets, acting as spacer to prevent the restacking of RGO sheets. This causes the sheets to be arranged in layers to form a porous, three-dimensional (3D) structure. Such morphology is most effective in facilitating the penetration of electrolyte within the matrix. Moreover, the components that were incorporated within the 3D continuous network greatly increased the nanocomposite's electrochemical utilization due to its high active surface area. Therefore, this nanocomposite is a promising candidate for the construction of high performance supercapacitor electrode [21]. Figure 3(c) shows that the discharge time for the ternary nanocomposite increased with the reduction of the current density applied. An abrupt drop in potential was observed, implying poor efficiency and 


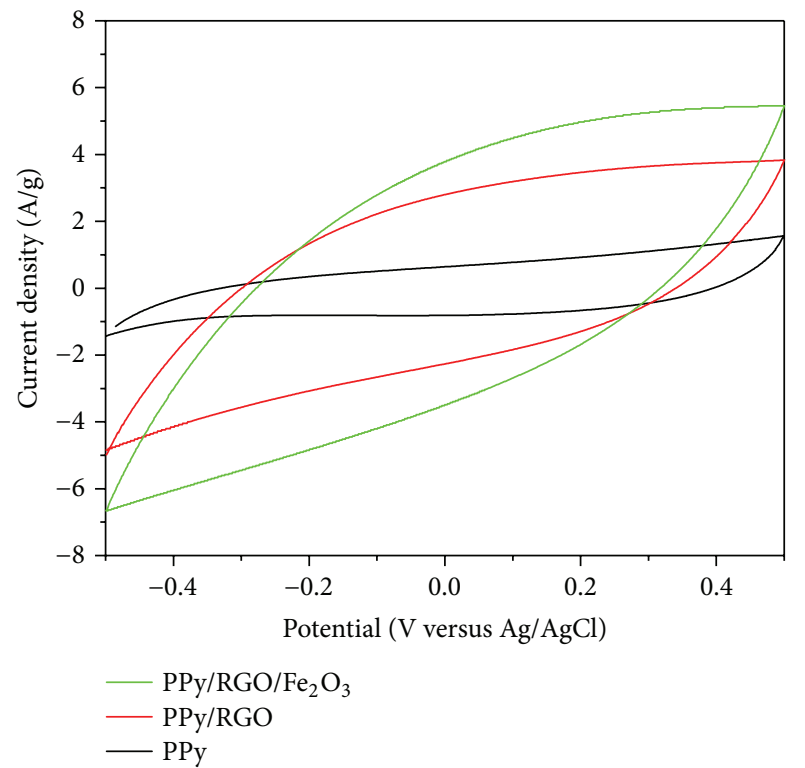

(a)

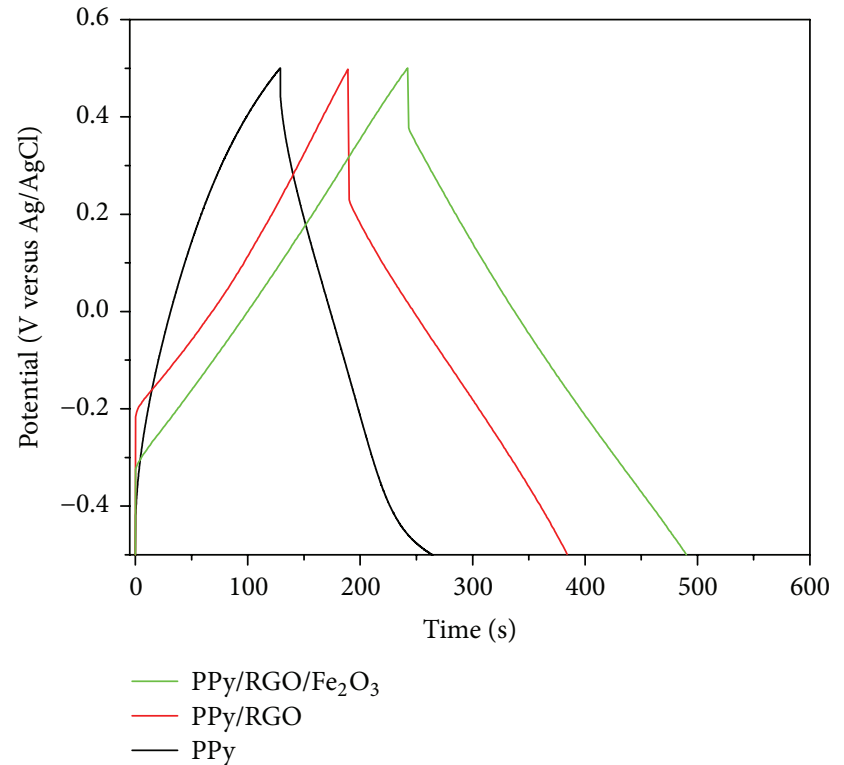

(b)

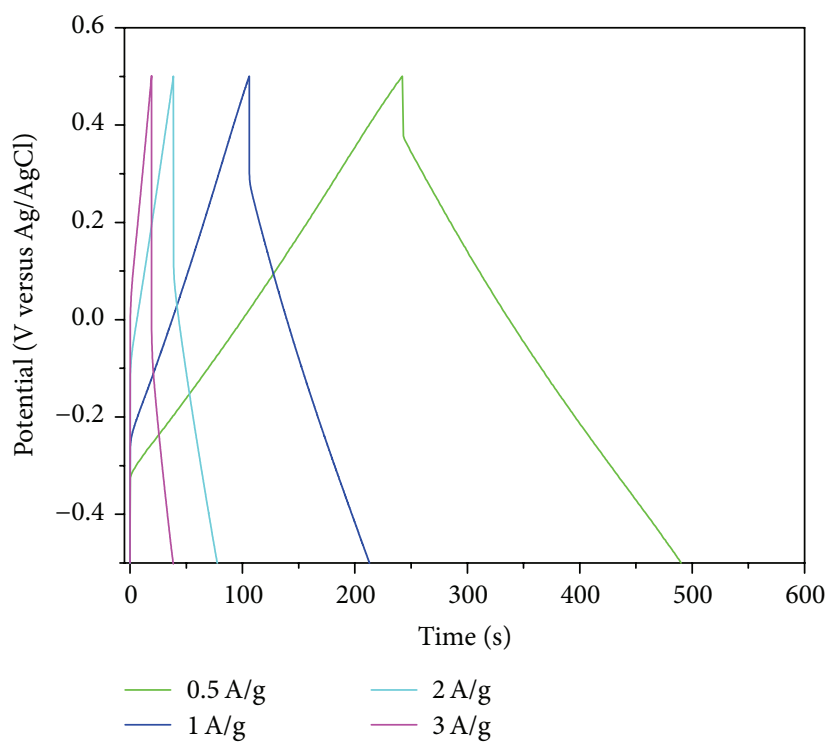

(c)

Figure 3: (a) Cyclic voltammograms (at $50 \mathrm{mV} / \mathrm{s}$ ) and (b) charge/discharge curves (at $0.5 \mathrm{~A} / \mathrm{g}$ ) for PPy, PPy/RGO, and PPy/RGO/Fe $\mathrm{O}_{3}$ nanocomposite and (c) charge discharge curves of $\mathrm{PPy} / \mathrm{RGO} / \mathrm{Fe}_{2} \mathrm{O}_{3}$ at a different current density.

shortened lifetime due to irreversible reactions within the cell [22].

3.3. EIS. Complementary to CV and galvanostatic charge/ discharge measurements, EIS provides useful information on the electrochemical frequency of a system for the measurement of redox reaction resistance. The charge transfer resistance, owing to a Faradaic redox process in the system, can be estimated from the diameter of a semicircle. In Figure 4(a), the diameter of the semicircle for the ternary nanocomposite is $9.5 \Omega$ compared to PPy and PPy/RGO which are $4.0 \Omega$ and $1.6 \Omega$, respectively. This indicates higher charge transfer resistance between the electrolyte and the ternary nanocomposite due to the poor conductivity of insulating iron oxide. The binary nanocomposite exhibited the lowest charge transfer resistance due to the formation of a conductive network between PPy and RGO within the nanocomposite matrix. The cycling stabilities of the nanocomposites are illustrated in Figure 4(b). It is well known that one major drawback of conducting polymers for supercapacitor electrode is the poor cycling stability during the charge/discharge process. The PPy and PPy/RGO film lost $93.6 \%$ and $92.0 \%$ of their capacitance performance after 200 cycles at $0.5 \mathrm{~A} / \mathrm{g}$. This deterioration is attributed 


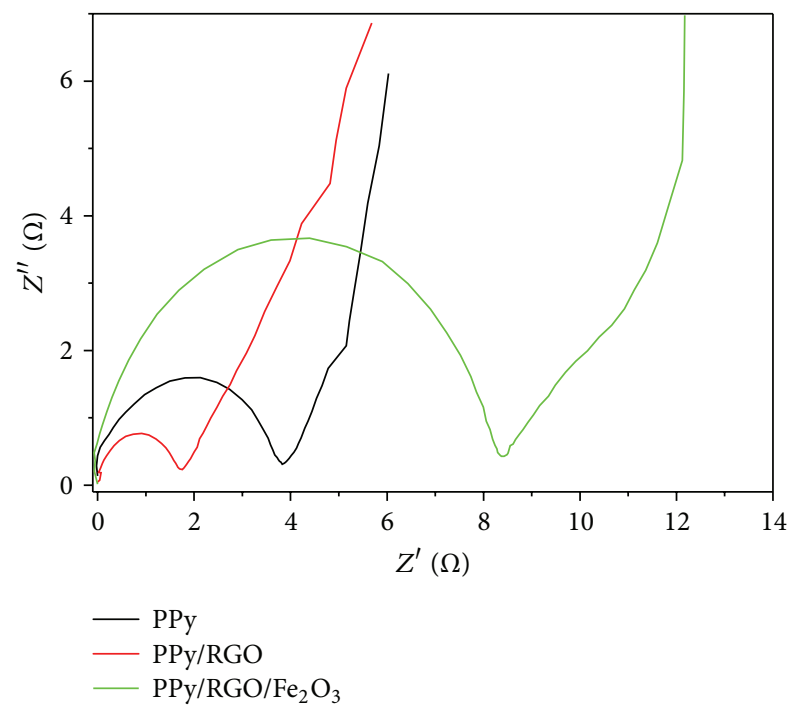

(a)

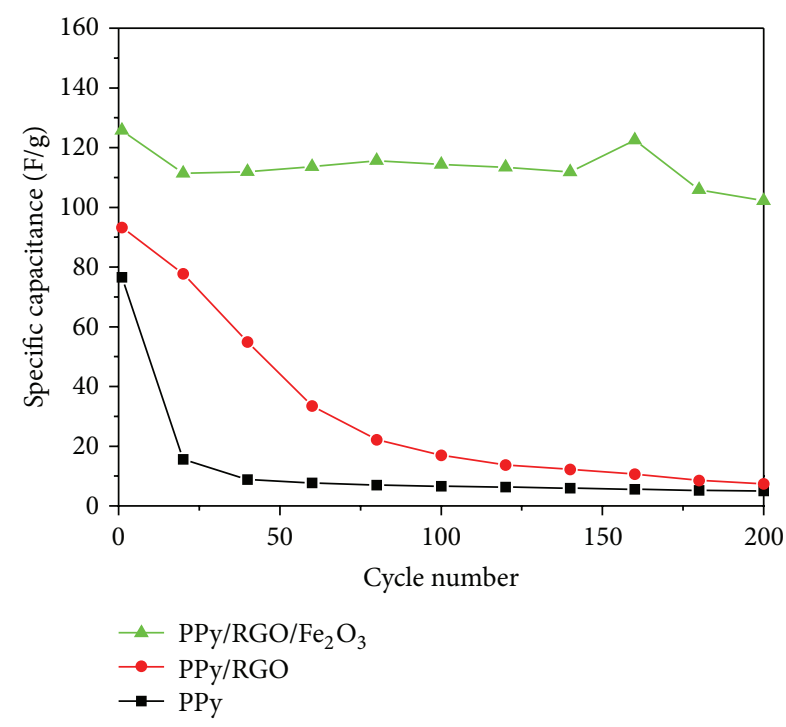

(b)

Figure 4: (a) Nyquist curves of PPy, PPy/RGO, and PPy/RGO/ $\mathrm{Fe}_{2} \mathrm{O}_{3}$ and (b) cycle stability tests for PPy, PPy/RGO, and PPy/RGO/Fe $\mathrm{O}_{3}$ at charge/discharge current density of $0.5 \mathrm{~A} / \mathrm{g}$.

to the formation of cracks in the polymer chains due to continuous swelling/shrinkage of polymer backbone during the charge/discharge cycles. However, the inclusion of $\mathrm{Fe}_{2} \mathrm{O}_{3}$ into the matrix of nanocomposite suppresses the cracking of electrode upon cycling and thus retains the large capacity. The initial and final specific capacitances are $125.7 \mathrm{~F} / \mathrm{g}$ and $102.2 \mathrm{~F} / \mathrm{g}$ after 200 cycles of charge and discharge, respectively, and are successfully maintained at $81.3 \%$.

\section{Conclusions}

Electrodeposition has been proven to be an effective method to prepare a PPy/RGO/Fe $\mathrm{O}_{3}$ nanocomposite film, which has potential for real application as a supercapacitor electrode material. Even though the presence of $\mathrm{Fe}_{2} \mathrm{O}_{3}$ increased the electron transfer resistivity between the electrolyte and ternary nanocomposite, it impedes the deterioration of the nanocomposite caused by continuous expansion and contraction during the charge/discharge cycles. $\mathrm{Fe}_{2} \mathrm{O}_{3}$ contributes to the cycling capability and stability of the nanocomposite, thus allowing the nanocomposite to manifest as a quality electrode material for supercapacitors.

\section{Acknowledgments}

This work was supported by Science Fund from the Ministry of Science, Technology and Innovation (06-01-04-SF1513) and High Impact Research Grant from the Ministry of Higher Education of Malaysia (UM.S/P/HIR/MOHE/21).

\section{References}

[1] H. N. Lim, N. M. Huang, C. H. Chia, and I. Harrison, "Inorganic nanostructures decorated graphene," in Advanced Topics in
Crystal Growth, Sukarno Ferreira, Ed., InTech, Rijeka, Croatia, 2013.

[2] P. Saville, "Polypyrrole: formation and use," Tech. Rep. DRDCTM-2005-004, Defence Research and Development Atlantic Dartmouth, 2005.

[3] G. B. Street, T. C. Clarke, R. H. Geiss et al., "Characterization of polypyrrole," Le Journal De Physique Colloques, vol. 44, pp. 599-606, 1983.

[4] J. Zhang and X. S. Zhao, "Conducting polymers directly coated on reduced graphene oxide sheets as high-performance supercapacitor electrodes," Journal of Physical Chemistry C, vol. 116, no. 9, pp. 5420-5426, 2012.

[5] Y. S. Lim, Y. P. Tan, H. N. Lim et al., "Polypyrrole/graphene composite films synthesized via potentiostatic deposition," Journal of Applied Polymer Science, vol. 128, pp. 224-229, 2013.

[6] Z. Sun, D. K. James, and J. M. Tour, "Graphene chemistry: synthesis and manipulation," The Journal of Physical Chemistry Letters, vol. 2, pp. 2425-2432, 2011.

[7] Y. Wang, Z. Shi, Y. Huang et al., "Supercapacitor devices based on graphene materials," Journal of Physical Chemistry C, vol. 113, no. 30, pp. 13103-13107, 2009.

[8] S. Biswas and L. T. Drzal, "Multilayered nanoarchitecture of graphene nanosheets and polypyrrole nanowires for high performance supercapacitor electrodes," Chemistry of Materials, vol. 22, no. 20, pp. 5667-5671, 2010.

[9] N. M. Huang, H. N. Lim, C. H. Chia, M. A. Yarmo, and M. R. Muhamad, "Simple room-temperature preparation of high-yield large-area graphene oxide," International Journal of Nanomedicine, vol. 6, pp. 3443-3448, 2011.

[10] Y. S. Lim, Y. P. Tan, H. N. Lim, N. M. Huang, and W. T. Tan, "Preparation and characterization of polypyrrole/graphene nanocomposite films and their electrochemical performance," Journal of Polymer Research, vol. 20, pp. 1-10, 2013.

[11] H.-H. Chang, C.-K. Chang, Y.-C. Tsai, and C.-S. Liao, "Electrochemically synthesized graphene/polypyrrole composites and 
their use in supercapacitor," Carbon, vol. 50, no. 6, pp. 23312336, 2012.

[12] S. Sahoo, G. Karthikeyan, G. C. Nayak, and C. K. Das, "Electrochemical characterization of in situ polypyrrole coated graphene nanocomposites," Synthetic Metals, vol. 161, no. 15-16, pp. 1713-1719, 2011.

[13] A. Davies, P. Audette, B. Farrow et al., "Graphene-based flexible supercapacitors: pulse-electropolymerization of polypyrrole on free-standing graphene films," Journal of Physical Chemistry C, vol. 115, no. 35, pp. 17612-17620, 2011.

[14] L. L. Zhang, S. Zhao, X. N. Tian, and X. S. Zhao, "Layered graphene oxide nanostructures with sandwiched conducting polymers as supercapacitor electrodes," Langmuir, vol. 26, no. 22, pp. 17624-17628, 2010.

[15] M. B. Sassin, A. N. Mansour, K. A. Pettigrew, D. R. Rolison, and J. W. Long, "Electroless deposition of conformal nanoscale iron oxide on carbon nanoarchitectures for electrochemical charge storage," ACS Nano, vol. 4, no. 8, pp. 4505-4514, 2010.

[16] R. A. Fisher, M. R. Watt, and W. J. Ready, "Functionalized carbon nanotube supercapacitor electrodes: a review on pseudocapacitive materials," ECS Journal of Solid State Science and Technology, vol. 2, pp. 3170-3177, 2013.

[17] W. Wang, Q. Hao, W. Lei, X. Xia, and X. Wang, "Graphene/ $\mathrm{SnO}_{2}$ /polypyrrole ternary nanocomposites as supercapacitor electrode materials," RSC Advances, pp. 10268-10274, 2012.

[18] B. Ding, X. Lu, C. Yuan et al., "One-step electrochemical composite polymerization of polypyrrole integrated with functionalized graphene/carbon nanotubes nanostructured composite film for electrochemical capacitors," Electrochimica Acta, vol. 62, pp. 132-139, 2012.

[19] Y. Xiong, J. Ye, X. Gu, and Q.-W. Chen, "Synthesis and assembly of magnetite nanocubes into flux-closure rings," Journal of Physical Chemistry C, vol. 111, no. 19, pp. 6998-7003, 2007.

[20] X.-F. Qu, G.-T. Zhou, Q.-Z. Yao, and S.-Q. Fu, "A sparticacid-assisted hydrothermal growth and properties of magnetite octahedrons," Journal of Physical Chemistry C, vol. 114, no. 1, pp. 284-289, 2010.

[21] Y. S. Lim, Y. P. Tan, H. N. Lim et al., "Potentiostatically deposited polypyrrole/graphene decorated nano-manganese oxide ternary film for supercapacitors," Ceramics International, 2013.

[22] M. D. Stoller and R. S. Ruoff, "Best practice methods for determining an electrode material's performance for ultracapacitors," Energy and Environmental Science, vol. 3, no. 9, pp. 1294-1301, 2010 . 

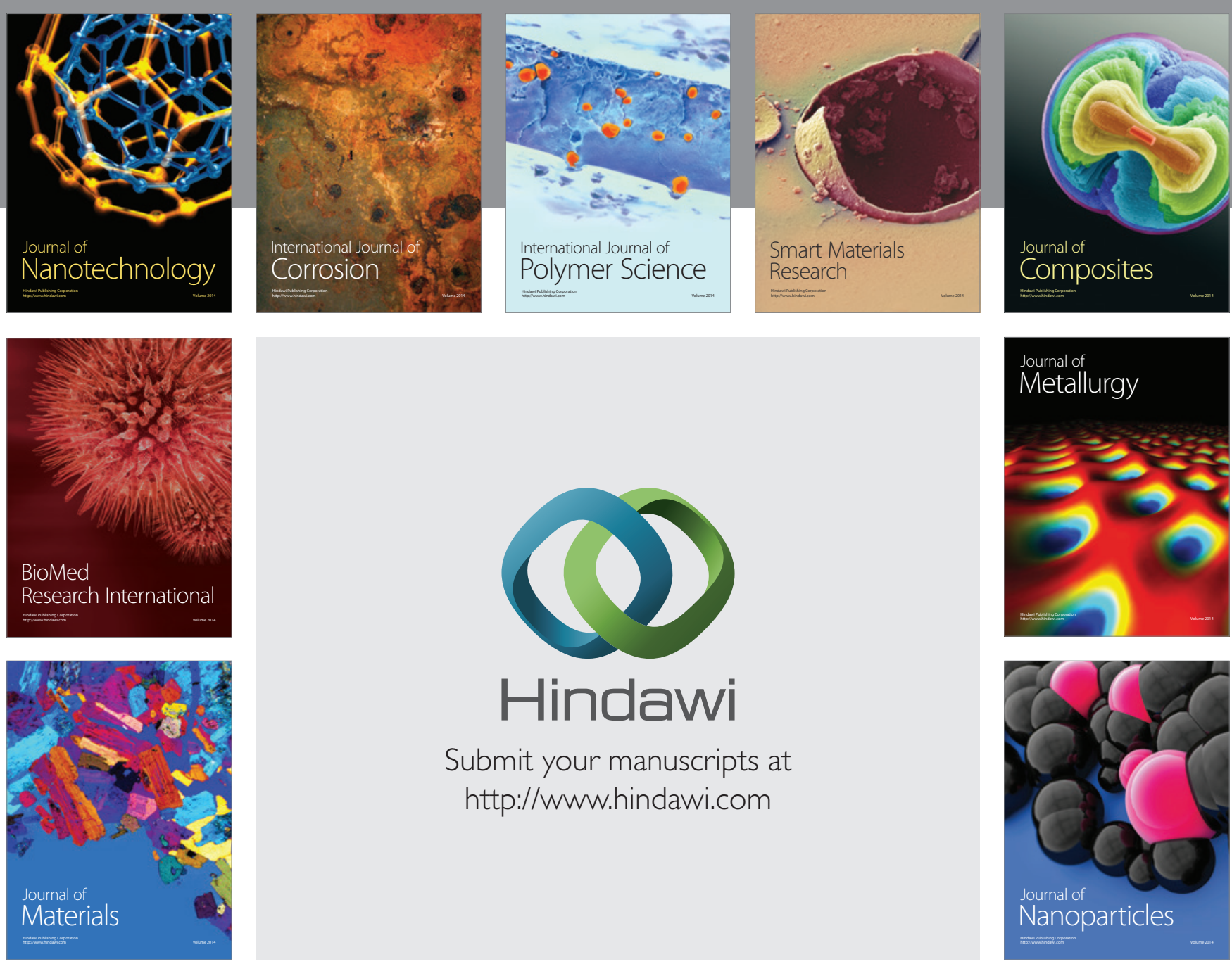

Submit your manuscripts at http://www.hindawi.com
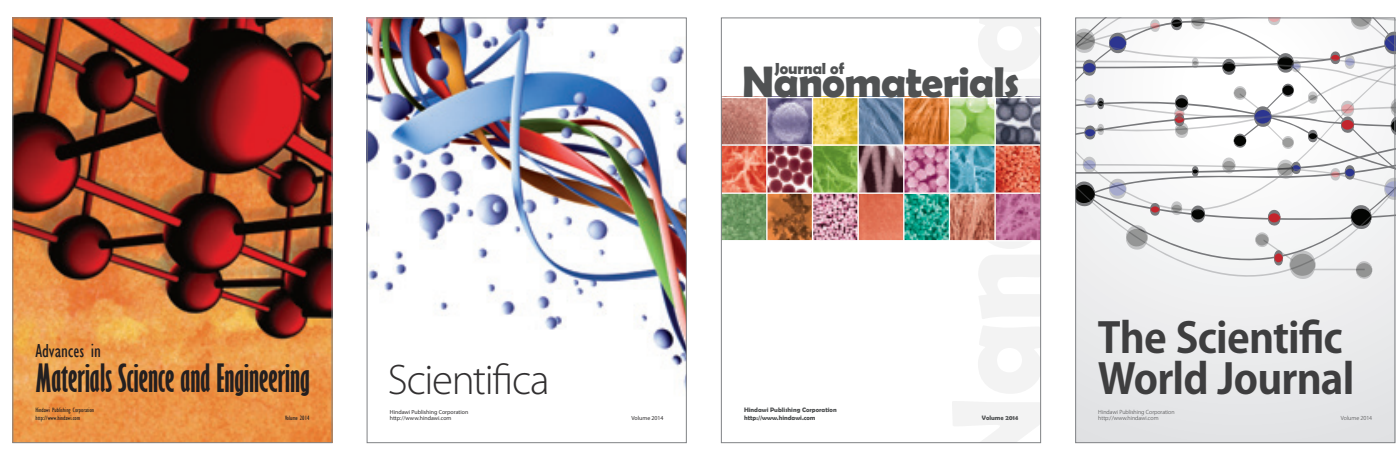

\section{The Scientific World Journal}
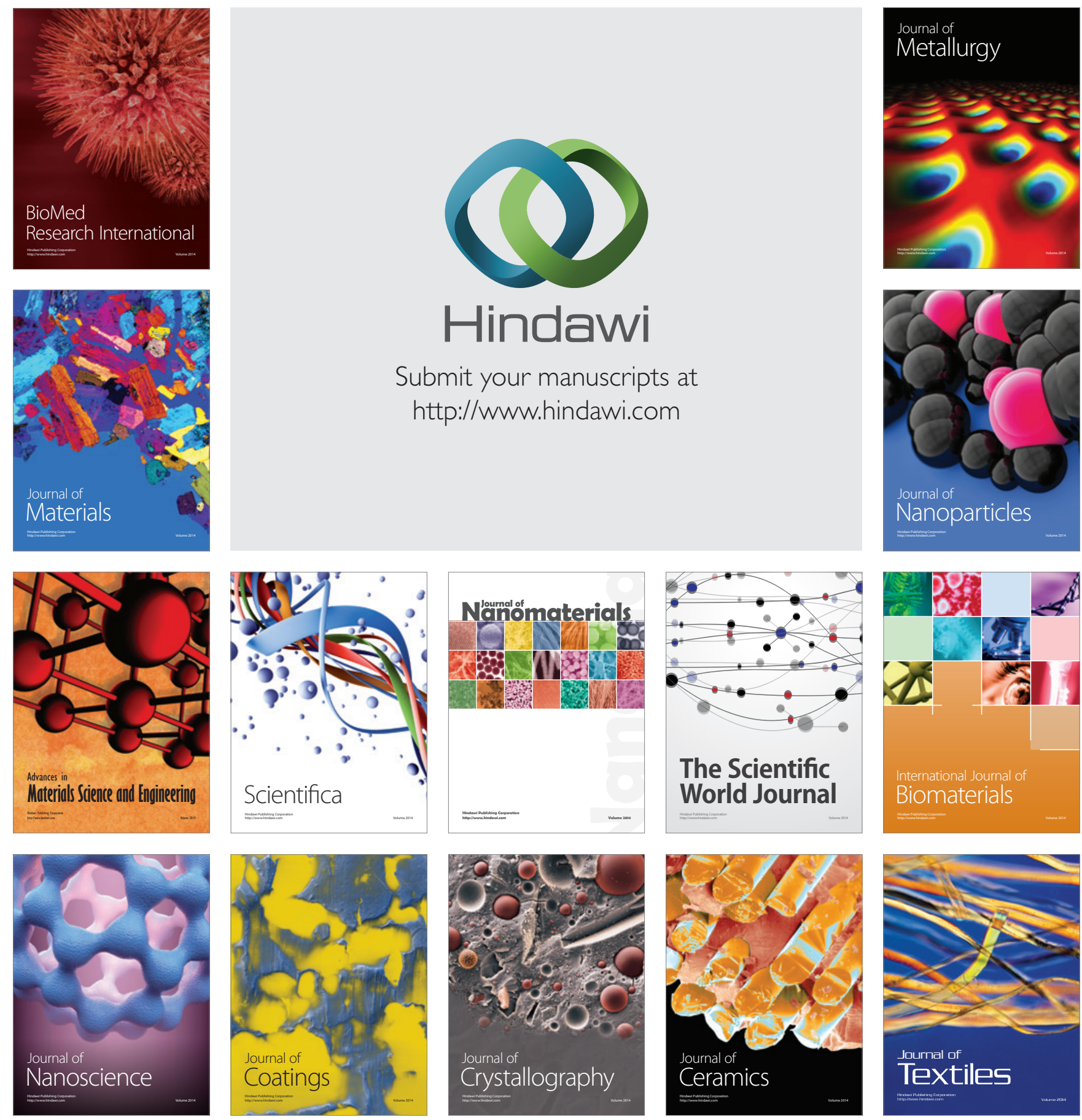